\title{
Thermal Analysis of Integrating Roof with Phase Change Materials for Energy Saving in Residential Buildings
}

\author{
Hayder M. Jaffal' ${ }^{1}$, Tawfeeq W. Mohammed ${ }^{2}$, Marwa H. Wasmi ${ }^{3}$ \\ ${ }^{1}$ College of Engineering, Al-Mustansiriyah University, Baghdad - Iraq
}

\begin{abstract}
The sector of air-conditioning in the residential building consumes most of the total electricity supplied for heating or cooling. Thus it has a major impact on the greenhouse gases and climate. Phase change materials (PCMs) are regarded as a possible solution for reducing the energy consumption of buildings by storing the heat and releasing it in certain times. The present study assists for the utilization of PCMs in the roof of residential building to absorb the heat comes from solar radiation during the daytime and releasing it to the inside nightly. Building considerations as well as thermo-physical properties of PCMs have been taken and measured experimentally. Results have shown that these materials have a good potential for reducing energy demand and satisfy comfortable thermal conditions. The obtained readings, from a rig model built for that purpose, showed that the indoor temperature could increase by 5$9^{\circ} \mathrm{C}$ in the winter compared to that measured in a traditional one. Furthermore, a simulation program depended on degree-days method explained that the energy consumption could be saved up to $75 \%$. Thus PCMs could submit encouraging suggestions toward the sustainability.
\end{abstract}

KEYWORDS : PCM, Heat storage, Energy saving, Solar energy, Sustainability.

\section{INTRODUCTION}

The majority of electric energy that supplied to a residential house is consumed by air-conditioning. For example in Iraq, air-condition units are responsible of more than $60 \%$ of the electrical power consumption in buildings during both summer and winter [1]. Hence, the reduction of energy loss is an epidemic issue of building energy control. One of the promising ideas of energy saving is the implementing of phase change materials (PCMs) in the building elements as integrated parts. Thermal energy storage can be integrated in buildings either by using sensible heat or latent heat. Sensible heat storage like building materials has been used for ages to store the thermal energy, but new applications of energy storage focused on materials that store the heat as latent heat to enhance the efficiency as well as control the lag time. A phase change material $(\mathrm{PCM})$ is a substance with a high latent heat of fusion during melting or solidification. Thus, it is capable of storing heat by absorbing it in daytime and releasing it nightly in controlled management of energy.

\footnotetext{
Academic Journal of Nawroz University

(AJNU) Volume 7, No 4 (2018).

Regular research paper : Published 21 December 2018

Corresponding author's e-mail : jaffal.env@uomustansiriyah.edu.iq

Copyright (02017 Hayder M. Jaffal ${ }^{1}$, Tawfeeq W.

Mohammed $^{2}$, Marwa H. Wasmi ${ }^{3}$.This is an open access

article distributed under the Creative Commons Attribution

License.
}

It is found that PCMs could absorb more than $86 \%$ of the exposed heat flux during daytime [2]. Many methods have been researched for the PCM applied to the buildings, such as wallboards containing PCMs [36], PCMs filled into sandwich wall, concrete walls, concrete block and concrete floors [7-16], PCMs as insulating permeating into the building brick and furniture [17-21]. Almost $80 \%$ of the studies have focused on the applications of PCMs in the walls as a development of encapsulation technology [22]. The recent study focuses on the integration of PCM in the roof of the building because the roof is the main source of thermal loss in the building envelope. Several promising developments are taking place in the field of using PCMs integrating with the roof of the buildings. Pasupathy et al. (2008) [23] attempted to study the thermal performance of an inorganic eutectic PCM based thermal storage system for thermal management in the roof of a residential building. They filled a steel container with PCM in the roof slab. The experimental tests were conducted in order to achieve optimum design for the selected location. Several simulation runs are made for the average ambient conditions for all the months in a year and for the various parameters of interest. The results show great contribution of using the PCM in decrease energy consumption rate. Nasrul Amri M. et al (2009) [24] proposed and optimized usage of PCMs encapsulated in slabs. Using a validated numerical model of the system, a parametric study was undertaken to investigate the impact of the slab 
thickness, gap between slabs and the mass flow rate. The storage system consists of several flat PCM slabs. A heat transfer fluid is assumed to flow between these slabs. No heat transfer to the surrounding is assumed. The study showed that, the system can deliver an energy storage density between $53 \%$ and $83 \%$ of the latent energy density of the PCM. Series of experimental investigations were carried out by Arizona Public Service (APS) in collaboration with Phase Change Energy Solutions (PCES). In a study carried out by Karthik M. [25] (2010) a Bio-PCM has used in the ceiling and the data were collected for two identical rooms with length, width and height as $4.8 \mathrm{~m} \times 3.6 \mathrm{~m} \times 2.4 \mathrm{~m}$. The structures had enclosed attic space with R-19 fiberglass insulation between 24" ceiling. Standard BioPCM mat with a PCM density of $1 \mathrm{lb}$. per cubic foot was installed in the ceiling. In addition, BioPCM mat with a PCM density of $0.56 \mathrm{lbs}$. per cubic foot was installed in the walls. The data recorded at the experimental site included ambient temperature and indoor temperature. It was found that a Bio-PCM with a melting point from 23 to $27^{\circ} \mathrm{C}$ led to maximum energy savings and is more suitable than other PCM temperature ranges for light weight building constructions. The experimental setup showed maximum energy savings of about $30 \%$, peak load shift for 1 hour and cost savings of about 30\%.In a study, carried out by Mushtaq T. et al (2013) [26], the thermal performance of a PCM for energy conservation in residential Iraqi building is presented in an experimental set up consisting of two identical test rooms. The study has used integrated PCM-aluminum panel on the roof of the building with circulated water pipes. The study conduct that there is energy saving of het by $47 \%$ compared to the roof without PCM panel. An article published by Stéphane G. et al (2015) [27] presents a new configuration of using phase change material (PCM) in a complex roof on a dedicated test cell. The PCM is inserted into an enclosed air space between the corrugated iron and the plasterboard. The experimental device was set up for a tropical and humid climate. Test was also implemented in multizone building software in order to automatically determine the thermal indicator. The PCM melting point was around $23{ }^{\circ} \mathrm{C}$. Results showed that the measured temperatures were more comfortable using the PCM's. Furthermore, the phase change usually occurs close to 10:00 PM nightly and continuing for 2 hours of heat releasing which is efficient to keep the space warmer by at least $2{ }^{\circ} \mathrm{C}$.

\section{Experimental Work}

The aim of this study is to design an effective heating system depending on the using of phase change materials (PCMs) in the roof of the building. The reason of selecting the roof is due to the most exposed to sun, hence maximum efficiency of the system. The study performance is evaluated depending of the thermal analysis. The work has been done experimentally using a rig model built for that purpose in Baghdad $\left(33^{\circ}, 44^{\circ}\right)$ at Al-Mustansiriyah University, Materials Engineering Department. The model is located at the terrace floor with dimensions of $1 \mathrm{~m} \times 1 \mathrm{~m} \times 1 \mathrm{~m}$, as shown in Fig. 1 . The walls and the floor are constructed from $1 \mathrm{~cm}$ common MDF (medium density fiber) with $4 \mathrm{~cm}$ internal insulation by EPS (Expanded polystyrene). While the roof is totally exposed to sun and covered by $5 \mathrm{~mm}$ clear glass. The PCMs layer is located downward the glass by $10 \mathrm{~cm}$. There is a slot in the space between the glass and the PCMs layer in order to put an insulated fiber at sunset time (till sunrise time) to avoid heat loss to the outside, as shown schematically in Fig. 2. The insulated walls and floor have a U-value of 1.35 $\mathrm{W} / \mathrm{m}^{2} . \mathrm{K}$ and covered with Alu-foils to reflect the radiation inside and assure well mixing of indoor air. The PCM material that used was Black Beeswax with thermo-physical properties [28] listed in Table 1. This material has been collected locally, and arranged to 18 pieces. The dimensions of each PCM piece were $30 \mathrm{~cm} \mathrm{x}$ $5 \mathrm{~cm}$ with $5-7 \mathrm{~mm}$ thickness. The PCMs pieces have arranged together in a net under the glass, as shown in Fig. 3. This mechanism (glazed roof, PCMs layer and insertable fiber in between) satisfies integrated and effective system with maximum heat storage as well as less heat losses. There is a hole of $9 \mathrm{~cm}^{2}$ in the north façade (rear-side) in order to satisfy infiltration by 0.4 $\mathrm{ACH}$ in average, which is necessary to avoid condensation as well as to offer fresh air. The experimental readings have been obtained during the sunny days of January 2018, where heating demand is required in the winter time in Iraq (mostly at night). The study served several instruments like: thermometer data logger (Lutron-Model TM-947SD) with temperature sensors (Type-K), as well as solar power meter (Lutron-Model SPM-1116SD). The sensors have set to measure the temperatures of: glass, PCMs, indoor air and outdoor air each 30 minutes during the entire day. The solar meter used to measure the maximum radiation each hour. 
TABLE (1) : Thermo-physical Properties of PCM Used

\begin{tabular}{|c|c|}
\hline Quantity & Units \\
\hline Name of PCM & Black Beeswax \\
\hline Density & $970 \mathrm{~kg} / \mathrm{m}^{3}$ \\
\hline Melting point & $62^{\circ} \mathrm{C}$ \\
\hline Specific heat of solid & $4700 \mathrm{~J} / \mathrm{kg} . \mathrm{K}$ \\
\hline Specific heat of liquid & $4900 \mathrm{~J} / \mathrm{kg} . \mathrm{K}$ \\
\hline Heat of fusion & $240 \mathrm{~kJ} / \mathrm{kg}$ \\
\hline Thermal conductivity & $0.4 \mathrm{~W} / \mathrm{m} . \mathrm{K}$ \\
\hline Total weight & $1.6 \mathrm{~kg}$ \\
\hline
\end{tabular}

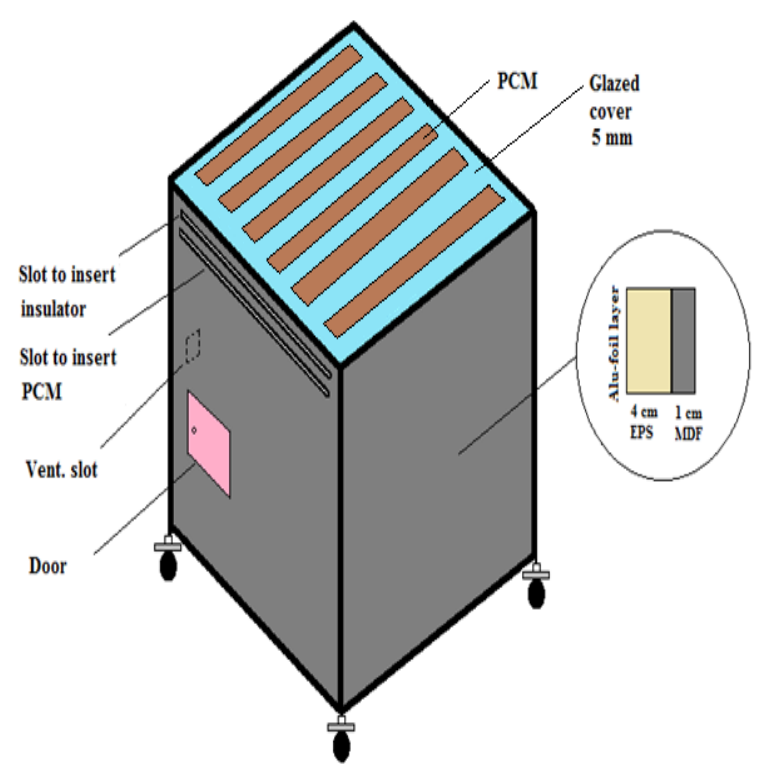

Fig (1) : Model built for the current study

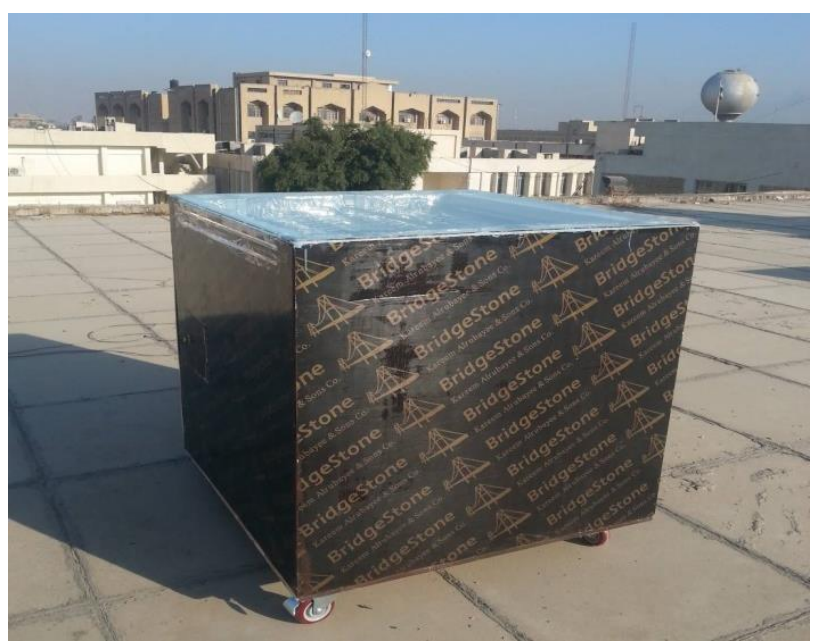

Fig (2) : Scheme explaining the features of the model

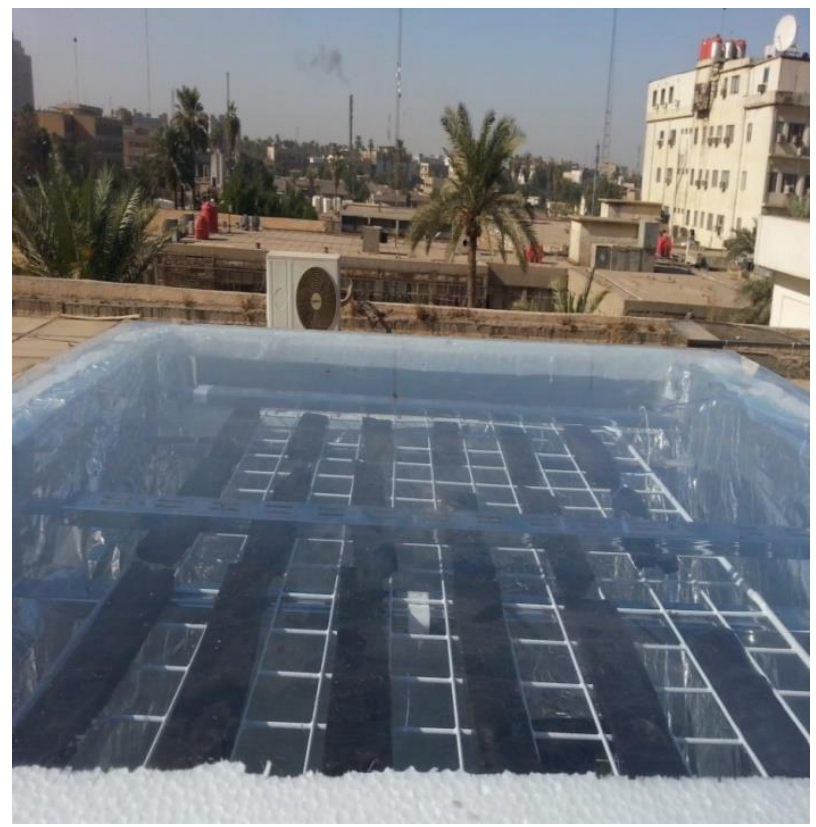

Fig (3) PCMs pieces arranged in a net under the glass

\section{Results And Discussions}

The study includes in-site measurements on the model built for the purpose of reducing the heating demand by using the PCMs. In January, the ambient temperature almost swings between 6 ${ }^{\circ} \mathrm{C}$ at night to $21{ }^{\circ} \mathrm{C}$ daytime on clear days with daytime duration of 10 hours and maximum solar radiation up to $600 \mathrm{~W} / \mathrm{m}^{2}$. In order to evaluate the performance of PCM in heat storage, the PCM layer was installed in many days and removed in other days. Samples of readings are selected to analyze in this study. For the case of with-PCM, the variation of outdoor, indoor, PCM and glass temperatures for the entire days of 2 Jan, 3 Jan and 4 Jan (2018) respectively are shown in Fig. 4, 5 and 6 . The outdoor temperatures were swinging from 8 ${ }^{\circ} \mathrm{C}$ (at 7:00 AM) to $19{ }^{\circ} \mathrm{C}$ (at 2:00 PM) with solar radiation up to $600 \mathrm{~W} / \mathrm{m}^{2}$. The average indoor temperature with $\mathrm{PCM}$ was $29^{\circ} \mathrm{C}$ with maximum value of $42{ }^{\circ} \mathrm{C}$ at 1:00 PM and minimum value of $17{ }^{\circ} \mathrm{C}$ at 7:00 AM. The indoor temperature at the night was decreasing from 26-17 ${ }^{\circ} \mathrm{C}$ with an average of 19 oC. Furthermore, the PCM temperature was swinging between 15-51 oC. For the case of without-PCM, variation of outdoor, indoor and glass temperatures for the entire days of 6 Jan, 7 Jan and 8 Jan (2018) respectively are shown in Fig. 7, 8 and 9. The outdoor temperatures were swinging from $7{ }^{\circ} \mathrm{C}$ (at 7:00 AM) to $20^{\circ} \mathrm{C}$ (at 2:00 PM) with solar radiation up to $600 \mathrm{~W} / \mathrm{m}^{2}$. The average indoor temperature without PCM was 22 
${ }^{\circ} \mathrm{C}$ with maximum value of $34{ }^{\circ} \mathrm{C}$ at 2:00 PM and minimum value of $10{ }^{\circ} \mathrm{C}$ at 7:00 AM. The indoor temperature at the night was decreasing from 19$10{ }^{\circ} \mathrm{C}$ with an average of $13{ }^{\circ} \mathrm{C}$. The results of comparison clarify the increasing of the indoor temperature due to the using of PCM by 5-9 ${ }^{\circ} \mathrm{C}$ most of the time. Also, the results showed that the PCMs can maintain indoor temperature above 20 ${ }^{\circ} \mathrm{C}$ for 12 hours daily, while for the case of withoutPCM it was only for 8 hours daily. These results were also emphasized in similar way by Sekar S. et al [29] in Indonesia, where they showed that the PCMs can maintain indoor temperature above 32 $\mathrm{C}$ for more than 8 hours daily in a model adopted for infants. Based on the current results it could estimate the heating load for the sample days to show the energy saving thus the thermal performance of PCM. A simulation program depended on degree-days method is established for current study and a base temperature of $20{ }^{\circ} \mathrm{C}$ is assumed to satisfy reasonable heating load. The results of calculation are shown in Table 2. The results explained that the energy consumption for the model with PCM was $126 \mathrm{~kJ} / \mathrm{m}^{2}$ daily as an average. On the other hand, the energy consumption for the model without PCM was 488 $\mathrm{kJ} / \mathrm{m}^{2}$ daily as an average. So, the energy saving using Black Beeswax could save the energy by $75 \%$. The energy efficient behavior of PCM material used in this study has led to a high level of energy saving and this is due to three main reasons: high thermal capacity, high latent heat of fusion and high thermal conductivity. Beeswax also possesses some super properties such as incongruent transition during melting, good chemical stability and non-toxicity. These properties rarely found in common PCM materials like paraffin. So Beeswax presents PCM as a good potential for reducing energy demand and satisfy comfortable thermal conditions.
TABLE (2) : Heating Load in January 2018 for Selected Samples

\begin{tabular}{|c|c|c|}
\hline $\begin{array}{c}\text { Day of } \\
\text { month }\end{array}$ & $\begin{array}{c}\text { Load } \\
\text { with PCM } \\
\left(\mathbf{k J} / \mathbf{m}^{\mathbf{2}}\right)\end{array}$ & $\begin{array}{c}\text { Load } \\
\text { without PCM } \\
\left(\mathbf{k J} / \mathbf{m}^{\mathbf{2}}\right)\end{array}$ \\
\hline 2 & 147 & - \\
\hline 3 & 128 & - \\
\hline 4 & 104 & - \\
\hline 5 & - & 471 \\
\hline 6 & - & 484 \\
\hline 7 & - & 507 \\
\hline 8 & -126 & 488 \\
\hline Avg. & \multicolumn{2}{|c|}{} \\
\hline
\end{tabular}

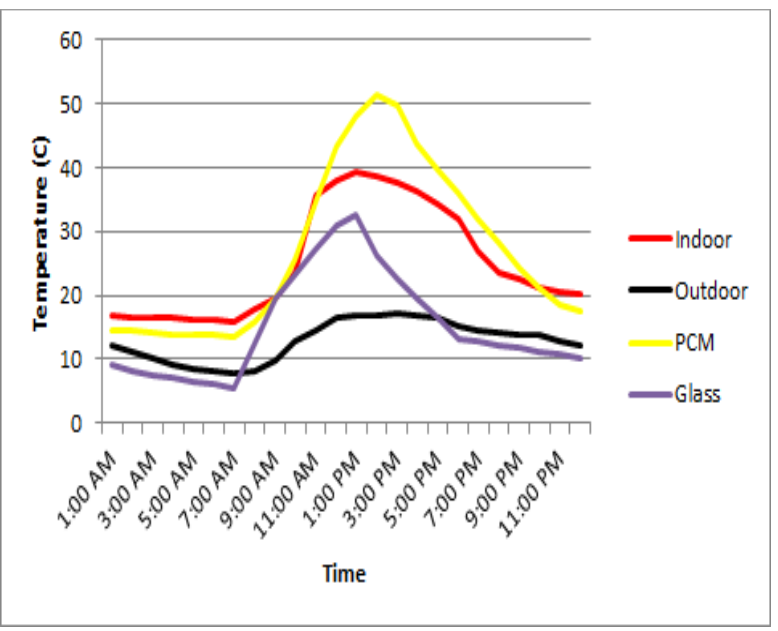

Fig (4) : Readings on 2 Jan (Max $\operatorname{Rad}=550 \mathrm{~W} / \mathrm{m}^{2}$ )

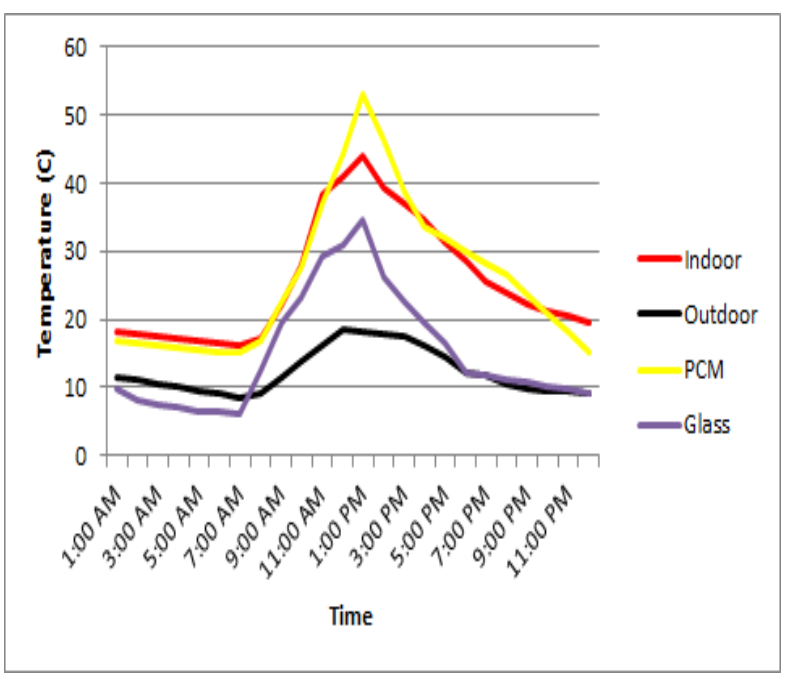

Fig (5) : Readings on 3 Jan (Max Rad=600 W/m²) 


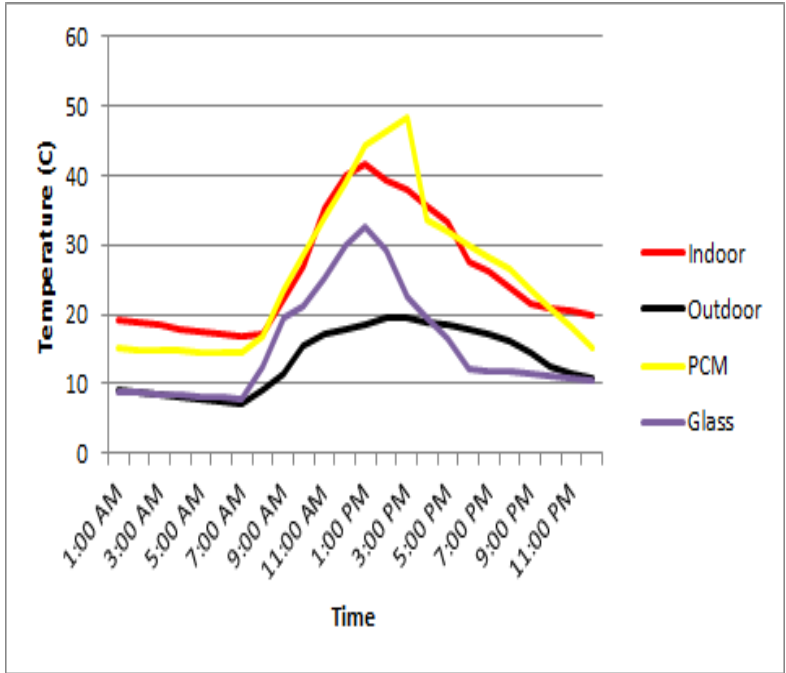

Fig (6) : Readings on 4 Jan (Max Rad=600 W/m²)

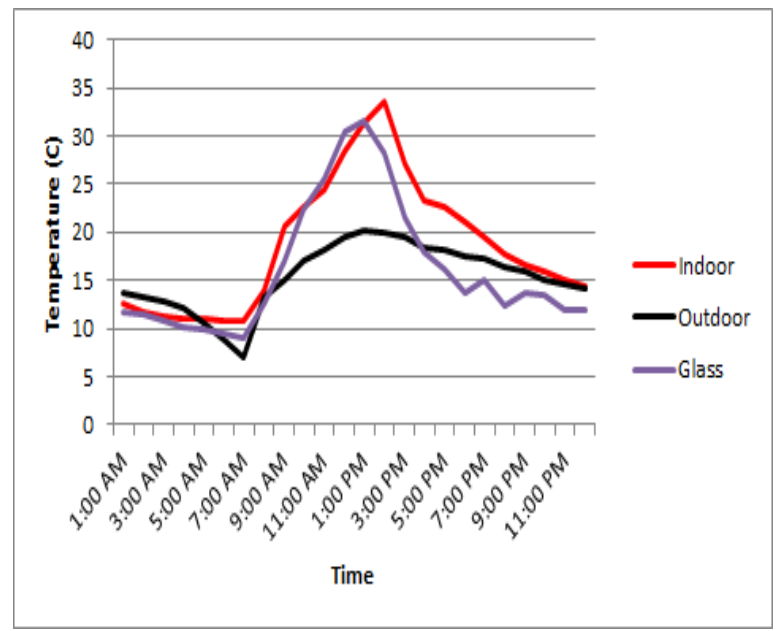

Fig (7) : Readings on 6 Jan (Max Rad=600 W/m2)

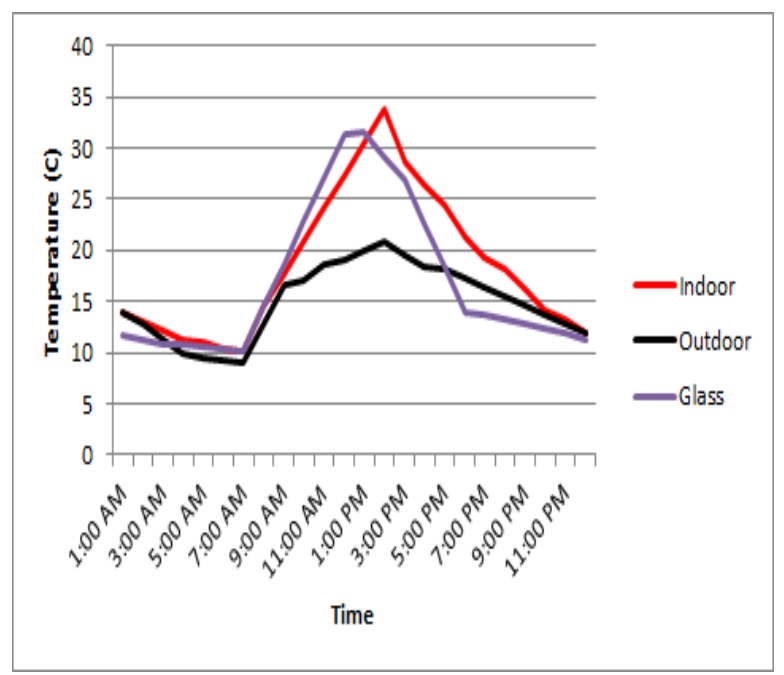

Fig (8) : Readings on 7 Jan (Max Rad=600 W/m²)

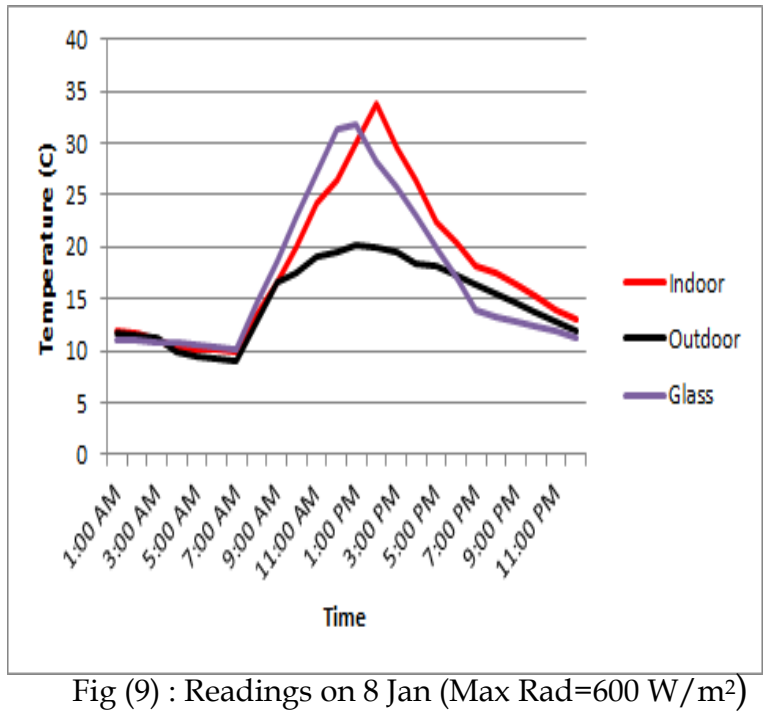

\section{Conclusion}

The recnt study submit a design for an effective heating system depending on the using of phase change materials (PCMs) as integrating layer in the roof of the building. The study performance is evaluated depending of the thermal analysis of the experimental readings. Results have shown that these materials have a good potential for reducing energy demand and satisfy comfortable thermal conditions. The indoor temperature for the model with PCM has an average value of $19{ }^{\circ} \mathrm{C}$ at night hence an increasing by $5-9{ }^{\circ} \mathrm{C}$ comparing to that measured for the model without PCM. Furthermore, a simulation program depended on degree-days method explained that the energy consumption for the model with PCM has an average value of $126 \mathrm{~kJ} / \mathrm{m}^{2}$ hence a reduction of $75 \%$ comparing to that calculated for the model without PCM. Hence, the PCM technology has significant advantages for residential buildings in terms of energy saving and reducing the discomfort hours. Besides that, the using of PCM adds thermal stability to the elements of building.

\section{Acknowledgment}

Authors are grateful to all support given by Dept. of Mechanical Engineering and Dept. of Materials Engineering, Al-Mustansiriyah University, BaghdadIraq.

\section{REFERENCES}

1. Ghanim K. Abdulsada \& Tawfeeq W. M. Salih (2015). "Experimental and theoretical study for the performance of new local thermal insulation in Iraqi building", Chapter 44 of the book: Renewable energy in the service of mankind (Vol I), Springer.

2. Rouhollah Ahmadi \& Amir Shahcheraghian (2015). "Energy saving in building using PCM on windows", Proceedings of 14th conference of international building performance simulation association, India, Dec. 7-9.

3. Alvarode Graciaa \& Luisa F.Cabeza (2015). "Phase change materials and thermal energy storage for 
buildings", Energy and Buildings, Vol. 103, pp (414-419). 4. Murat Kenisarin \& Khamid Mahkamov (2016). "Passive thermal control in residential buildings using phase change materials", Renewable and Sustainable Energy Reviews, Vol. 103, pp (371-398).

5. Murat Kenisarin \& Khamid Mahkamov (2017). "Experimental study on thermal performance of phase change material passive and active combined using for building application in winter", Applied Energy, Vol. 206, pp (293-302).

6. Kong, Chengqiang Yao, Pengfei Jie, Yun Liu, Chengying Qi \& Xian Rong (2017). "Development and thermal performance of an expanded perlite-basedphase change material wallboard for passive cooling in building"', Energy and Buildings, Vol. 152, pp (547-557).

7. Yusuf A. Kara (2016). "Diurnal performance analysis of phase change material walls", Applied Thermal Engineering, Vol. 102, pp (1-8).

8. Subbiah M. (2017). "Analysis of Solar Heat Gains and Environmental Impact of the Phase Change Material (PCM) Wall", Innovative Energy \& Research, Vol. 6, pp (1$6)$.

9. Chenglong Luo, Lijie Xu, Jie Ji, Mengyin Liao \& Dan Sun (2017). "Experimental study of a modified solar phase change material storage wall system", Energy, Vol. 128, pp (224-231).

10. Lidia Navarro, Alvaro de Gracia, Albert Castell, Servando Álvarez \& Luisa F.Cabeza (2014). "Design of a prefabricated concrete slab with PCM inside the hollows", Energy Procedia, Vol. 57, pp (2324-2332).

11. Ahmad Hasan, Khaled A. Al-Sallal, Hamza Alnoman, Yasir Rashid \& Shaimaa Abdelbaqi (2016). "Effect of Phase Change Materials (PCMs) Integrated into a Concrete Block on Heat Gain Prevention in a Hot Climate", Sustainability, Vol. 8, pp (1-14).

12. Jianli Li, Ping Xue, Hong He, Wenying Ding \& Jinmin Han (2009). "Preparation and application effects of a novel form-stable phase change material as the thermal storage layer of an electric floor heating system", Energy and Buildings, Vol. 41, pp (871-880).

13. Entrop A.G, Brouwers H.J.H \& Reinders A.H.M.E (2011). "Experimental research on the use of microencapsulated Phase Change Materials to store solar energy in concrete floors and to save energy in Dutch houses", Solar Energy, Vol. 85, pp (1007-1029).

14. Xing Jin \& Xiaosong Zhang (2011). "Thermal analysis of a double layer phase change material floor", Applied Thermal Engineering, Vol. 31, pp (1576-1581).

15. Hyun Bae Kim, Masayuki Mae, Youngjin Choi \& Takeshi Kiyota (2017). "Experimental analysis of thermal performance in buildings with shape stabilized phase change materials", Energy and Buildings, Vol. 152, pp (524533).

16. Esam M. Alawadhi (2008). "Thermal analysis of a building brick containing phase change material", Energy and Buildings, Vol. 40, pp (531-557).

17. Xiangfei Kong, Shilei Lu, Jingyu Huang, Zhe Cai \&
Shasha Wei (2013). "Experimental research on the use of phase change materials in perforated brick rooms for cooling storage", Energy and Buildings, Vol. 62, pp (597604).

18. Xu Wang, Hang $\mathrm{Yu} \& \mathrm{Lu} \mathrm{Li}$, Mei Zhao (2016). "Experimental assessment on the use of phase change materials (PCMs)-bricks in the exterior wall of a full-scale room", Energy Conversion and Management, Vol. 120, pp (81-89).

19. Karunesh Kant, A. Shukla \& Atul Sharma (2017). "Heat transfer studies of building brick containing phase change materials", Solar Energy, Vol. 155, pp (1233-1242).

20. Lu Li, Hang Yu \& Rui Liu (2017). "Research on composite-phase change materials (PCMs)-bricks in the west 1 wall of room-scale cubicle: mid-season and summer day cases", Building and Environment, Vol. 123, pp (494503).

21. Hicham Johra \& Per Heiselberg (2016). "Influence of internal thermal mass on the indoor thermal dynamics and integration of phase change materials in furniture for building energy storage: A review", Renewable and Sustainable Energy Reviews, Vol. 69, pp (19-3).

22. Kuznik F., David D., Johannes K. \& J. J. Roux (2011). "A review on phase change materials integrated in building walls", Renewable and Sustainable Energy Reviews, Elsevier, 15 (1), pp.379-391.

23. Pasupathy A., Athanasius L., Velraj R. \& Seeniraj R. (2008). "Experimental investigation and numerical simulation analysis on the thermal performance of a building roof incorporating phase change material $(\mathrm{pcm})$ for thermal management", Applied Thermal Engineering 28 (5-6), $556-565$.

24. Nasrul Amri M., Martin B. \& Frank B. (2009). "Optimisation of A Phase Change Thermal Storage System", World Academy of Science, Engineering and Technology 56, P.P. 765-769.

25. Karthik M. (2010). "Application of phase change material in buildings: field data vs. EnergyPlus simulation", Master thesis submitted to Arizona State University.

26. Mushtaq T. H, Ahmed Q. M \& Hasanain M.H. (2013). "Experimental and numerical study of thermal performance of a building roof including phase change material (PCM) for thermal management", Global Advanced Research Journal of Engineering, Technology and Innovation, Vol. 2(8), pp. 231-242.

27. Stéphane G., Frédéric M., Dimitri B., Bruno M. \& Harry B. (2015), "Experimental investigation on a complex roof incorporating phase change material", Energy and Buildings, Elsevier, 108, pp.36-43.

28. Jyothi J. (2006). "Physico-chemical properties of Beewax of Apis species," Journal of Entomological Research, vol. 30, pp. 347-349.

29. Sekar S., Nandy P., Muhammad A. \& Fitri A. (2016). "The utilization of paraffin and beeswax as heat energy storage in infant incubator", ARPN Journal of Engineering and Applied Sciences, VOL. 11, NO. 2. 